\title{
Aggregation of Aeromonas Gum in Aqueous Solution
}

\author{
Lina ZHANG, ${ }^{\dagger}$ Xiaojuan XU, Guowen JiANG, \\ Hideki IIJIma, ${ }^{*}$ and Hiromichi TsuchiYA** \\ Department of Chemistry, Wuhan University, Wuhan 430072, China \\ * Chemicals Technology Department IV, Asahi Chemical Industry Co., Ltd., \\ Miyazaki 882-0847, Japan \\ ** Fourth Specialty Chemicals Sales Department, Asahi Chemical Industry Co., Ltd., \\ Tokyo 100-8440, Japan
}

(Received July 21, 1998)

\begin{abstract}
Aeromonas (A) gum, a stabilizer, and thickening agent of food, is composed of xylose, mannose, galactose, glucose, and mannuronic acid. Weight-average molecular weights $M_{w}$ and intrinsic viscosities $[\eta]$ of the unfractionated A gum and three fractions in water, $0.5 \mathrm{M} \mathrm{NaCl}$ aqueous solution and cadoxen were studied by light scattering and viscometry. Experimental results showed that $\mathrm{A}$ gum exists as an aggregate in $0.5 \mathrm{M} \mathrm{NaCl}$ aqueous solution and mainly as a single chain in cadoxen. The apparent aggregation number $\left(N_{\mathrm{ap}}\right)$ of $\mathrm{A}$ gum in $0.5 \mathrm{M} \mathrm{NaCl}$ aqueous solution was $c a$. 22 , and decreased with increasing sample molecular weight. Change of aggregation and disaggregation of $\mathrm{A}$ gum in $0.5 \mathrm{M} \mathrm{NaCl}$ aqueous/cadoxen mixtures occurred from 0 to 0.4 of $v_{\text {cad }}$ (volume fraction of cadoxen), and was reversible. The stable aggregation of A gum in $0.5 \mathrm{M} \mathrm{NaCl}$ aqueous $/ 3 \%$ cadoxen mixture was achieved after $150 \mathrm{~min}$.

KEY WORDS Aggregation/Aeromonas Gum / Light Scattering / Viscometry / Polysaccharide Aqueous Solution /
\end{abstract}

Water-soluble polysaccharides, whose viscosity is very high, are of increasing interest as thickening agents in food and in enhanced oil recovery. Aeromonas (A) gum, an extracellular polysaccharide, produced by strains Aeromonas nichidenii, has been used as an additive for food such as a thickening agent and stabilizer. ${ }^{1,2} \mathrm{~A}$ gum is composed of xylose, mannose, galactose, glucose, and mannuronic acid, and its molecular weight is $c a$. $10^{5}-10^{7}$ by gel filter. ${ }^{2}$ Understanding of the relation between solution behavior in different solvents and thickening is very important for application. In general, large enhancement in viscosity of the polymer is attributable to chain stiffness ${ }^{3,4}$ and large hydrodynamic volume of polyelectrolyte caused by electrostatic force because of the charge groups in water. ${ }^{5,6}$

A water-soluble glucan A isolated from the fruit body of Auricularia auricula-judae, which dissolves in water as single-stranded helical chains, exhibits excessively high viscosity, ${ }^{7}$ and intrinsic viscosity $[\eta]$ in water- $\mathrm{Me}_{2} \mathrm{SO}$ mixtures decreased sharply in the $w_{\mathrm{Me}_{2} \mathrm{So}}$ (weight fraction of $\mathrm{Me}_{2} \mathrm{SO}$ ) range of $0.6-0.8 .^{8}$ Interestingly, $\beta$-D-glucan PC3 from Poria cocos sclertium forms aggregates in $20 \%$ cadoxen aqueous solution and disassociates into single chains in cadoxen, and the change of aggregation and disaggregation occurred in the $v_{\text {cad }}$ (volume fraction of cadoxen) range from 0.2 to $0.3 .^{9} M_{w}$ and $[\eta]$ in $20 \%$ cadoxen aqueous solution are much larger than those in cadoxen. Many aggregation phenomena investigated by light scattering have been reported for synthesized copolymer, ${ }^{5}$ sulfonated poly(phenylene terephthalamide) ${ }^{6}$ trichosanthin, ${ }^{10}$ block polyelectrolyte, ${ }^{11}$ polystyrene/polyimide block copolymers, ${ }^{12}$ and $\omega$ and $\alpha, \omega$-metal sulfonato polystyrene ${ }^{13}$ in solution. In these cases, strong interchain interaction results in a large equilibrium constant for association in aqueous or other solutions, so that the polymer hardly exists in the

\footnotetext{
$\dagger^{\dagger}$ To whom correspondence should be addressed.
}

single-chain state. ${ }^{6}$ Cadoxen has been used as a solvent, which breaks the strong intermolecular interaction of polysaccharides. Xanthan dissolves in $0.1 \mathrm{M} \mathrm{NaCl}$ aqueous solution as double-stranded helix, which is sustained by intra- and intermolecular hydrogen bonds, but as single chain in cadoxen at $25^{\circ} \mathrm{C} .^{3}$ In this work, the aggregation and solution behavior of $\mathrm{A}$ gum in $0.5 \mathrm{M}$ $\mathrm{NaCl}$ aqueous solution and cadoxen were studied using light scattering and viscometry.

\section{EXPERIMENTAL}

\section{Preparation and Analysis of Samples}

A gum was provided by Fourth Specialty Chemicals Sales Department, Asahi Chemical Industry Co., Ltd. in Japan. A gum aqueous solution ( $5500 \mathrm{~mL} 0.56 \mathrm{wt} \%$ ) was prepared, and the water-insoluble gum was removed by centrifugation. Half of the clear solution obtained was diluted to $0.1 \mathrm{wt} \%$, and according to the nonsolvent addition method fractionated by the addition of isopropanol as a precipitant at room temperature. Isopropanol was added until the solution turned slightly milk-white. After standing for $12 \mathrm{~h}$, the precipitate was removed by centrifugation to obtain the first fraction. The liquid was subjected to next fractionation step. Eight fractions obtained were dialyzed to purity, and rotary evaporated at reduced pressure below $45^{\circ} \mathrm{C}$ to dry. The unfractionated sample $A$ and three fractions A-5, A-6, and A-7 were used in this work.

The IR spectra of the samples were recorded with a Nicolet FT-IR spectrometer. Each sample showed IR absorption at $890 \mathrm{~cm}^{-1}$ indicative of $\beta$-glucoside as well as at $1610 \mathrm{~cm}^{-1}\left(\mathrm{CO}_{2}^{-}\right)$and $800 \mathrm{~cm}^{-1}$ (mannoside), similar to acidic heteropolysaccharide. ${ }^{14}$ High performance liquid chromatography (HPLC) of sugars, obtained by hydrolyzing the samples with trifluoroacetic acid in sealed tubes at $100^{\circ} \mathrm{C}$, was performed on HPLC (LC-6A, Shimadzu) equipped with u-Bondapak $\mathrm{NH}_{2}$ 
$(7.8 \times 300 \mathrm{~mm})$ using refractometer detector. A mixture of $\mathrm{CH}_{3} \mathrm{CN} / \mathrm{H}_{2} \mathrm{O} / \mathrm{CH}_{3} \mathrm{OH}(85: 10: 5$ by volume $)$ at $25^{\circ} \mathrm{C}$ was used as the mobile phase. The colorimetric method of Dische's carbozole reaction for uronic acid in the presence of borate ${ }^{15}$ was used for analysis of mannuronic acid. An absorbance of the reacted solution was monitored at $530 \mathrm{~nm}$ by UV spectroscopy (UV-160A, Shimadzu). The determined components of the samples A, A-5, A-6, and A-7 are summarized in Table I.

\section{Light Scattering}

Scattering light intensity was observed on a dynamic light scattering spectrophotometer (DLS-700, Otsuka Electronics Co.) with $\lambda=633 \mathrm{~nm}$ in an angular range from 30 to $150^{\circ}$ at $15^{\circ}$ intervals at $25^{\circ} \mathrm{C}$. Solutions were prepared with solvents of $0.5 \mathrm{M} \mathrm{NaCl}$ aqueous solution and cadoxen, respectively. Measurements were performed at $1 \times 10^{-4}-8 \times 10^{-4} \mathrm{~g} \mathrm{~mL}^{-1}$. Optical clarification of the solutions was achieved using a sand filter, with subsequent filtration through a $0.2-\mu \mathrm{m}$ pore-size filter (M-HJV) for $\mathrm{NaCl}$ aqueous solution or a $0.45-\mu \mathrm{m}$ pore-size filter (Nylon Acrodisc, Gelman Sci. Inc.) for cadoxen into the scattering cell. The refractive index increments $(\mathrm{d} n / \mathrm{d} c)$ were measured with a double-beam differential refractometer (DRM-1020, Otsuka Electronics Co.) at $633 \mathrm{~nm}$ and $25^{\circ} \mathrm{C}$. $\mathrm{d} n / \mathrm{d} c$ was measured to be $0.122 \mathrm{~mL} \mathrm{~g}^{-1}$ for the sample A and fractions in $0.5 \mathrm{M}$ $\mathrm{NaCl}$ aqueous solution, dialyzed by using a regenerated cellulose tube for three days before use. $\mathrm{d} n / \mathrm{d} c$ of $0.161 \mathrm{~mL} \mathrm{~g}^{-1}$ for glucan in cadoxen under the same experimental conditions ${ }^{9}$ was used as $\mathrm{A}$ gum and its fractions in cadoxen.

\section{Viscometry}

Viscosity of the solutions was measured using a Ubbelodhe capillary viscometer and low-shear three-bulb capillary viscometer at $25 \pm 0.1^{\circ} \mathrm{C}$. Water, $0.5 \mathrm{M} \mathrm{NaCl}$ aqueous solution, cadoxen, and $0.5 \mathrm{M} \mathrm{NaCl}$ aqueous/ cadoxen mixtures were used as solvents. The intrinsic viscosity $[\eta]$ of $\mathrm{A}$ gum in aqueous solution depended on the shear rate $\dot{\gamma}$. Huggins and Kraemer plots were used to estimate $[\eta]$ of the samples in $0.5 \mathrm{M} \mathrm{NaCl}$ aqueous solution, and zero shear-rate viscosity $[\eta]_{0}$ was obtained from plots of $[\eta]$ against $\dot{\gamma} .[\eta]$ of the samples in cadoxen, variant $\mathrm{NaCl}$ aqueous solution and $0.5 \mathrm{M}$ $\mathrm{NaCl}$ aqueous/cadoxen mixtures were measured using a Ubbelodhe viscometer and calculated by Huggins and Kraemer plots. [ $\eta]$ of the samples in water were measured using the Ubbelodhe viscometer and estimated by Fuoss experimental equation suitable for poly= electrolyte solution as following:

$$
\left(\eta_{\mathrm{sp}} / c\right)^{-1}=([\eta])^{-1}+B([\eta])^{-1} c^{1 / 2}
$$

where $c$ is concentration, $\mathrm{g} \mathrm{mL}^{-1}$.

\section{RESULTS AND DISCUSSION}

\section{Molecular Weight and Aggregation Number}

Static light scattering is convenient for measuring weight-average molecular weight $M_{w}$ and mean-square radii of gyration $\left\langle S^{2}\right\rangle$ of polymers. However, light scattering does not give true values of $M_{w}$ and $\left\langle S^{2}\right\rangle$ for heterogeneous copolymers. Fortunately, the A gum
Table I. Components and content of samples

\begin{tabular}{cccccc}
\hline & \multicolumn{5}{c}{ Components sugar ${ }^{\text {a }}$ Sample } \\
\cline { 2 - 6 } & Glc & Man & Xyl & Gal & ManA \\
\hline A & 1.0 & 2.0 & 1.0 & 0.3 & 0.8 \\
A-5 & 1.1 & 2.5 & 1.0 & 0.3 & 1.0 \\
A-6 & 1.5 & 2.9 & 1.0 & 0.2 & 1.7 \\
A-7 & 2.2 & 3.9 & 1.0 & 0.3 & 1.5
\end{tabular}

${ }^{a}$ Glc, glucose; Man, mannose; Xyl, xylose; Gal, galactose; ManA, mannuronic acid.

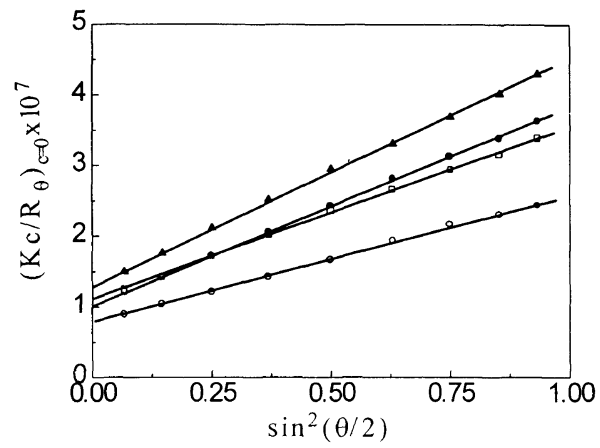

Figure 1. Angular dependence of $\left(K c / R_{\theta}\right)_{c=0}$ of $\mathrm{A}(\mathbf{\Delta})$, A-5 (O), $\mathrm{A}-6(\bigcirc)$, and $\mathrm{A}-7(\square)$ in $0.5 \mathrm{M} \mathrm{NaCl}$ aqueous solution at $25^{\circ} \mathrm{C}$.

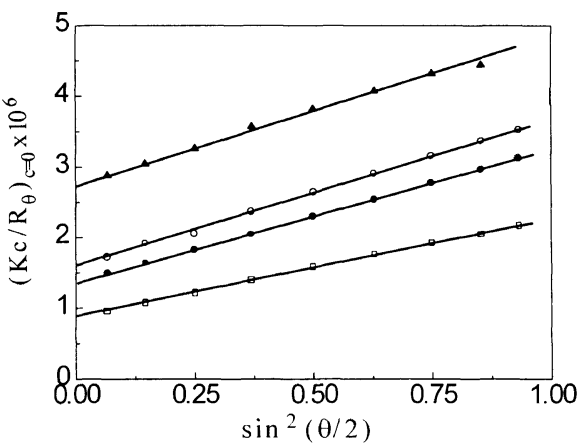

Figure 2. Angular dependence of $\left(K c / R_{\theta}\right)_{c=0}$ of $\mathrm{A}(\mathbf{\Delta}), \mathrm{A}-5(\mathrm{O}), \mathrm{A}-6$ (O), and A-7 ( $\square)$ in cadoxen at $25^{\circ} \mathrm{C}$

components given in Table I can be expected to have similar refractive indices, so that apparent weight-average molecular weight and apparent radii of gyration directly derived may be equated to the true values without significant error.

Figures 1 and 2 illustrate the angular dependence of $\left(K c / R_{\theta}\right)_{c=0}$ of four samples in $0.5 \mathrm{M} \mathrm{NaCl}$ aqueous solution and cadoxen at $25^{\circ} \mathrm{C}$, respectively. $K$ is the light scattering constant, and $R_{\theta}$ is the reduced Rayleigh ratio at angle $\theta . M_{w}$ and $\left\langle S^{2}\right\rangle^{1 / 2}$ of the samples are summarized in Table II. $M_{w}$ of the samples A, A-5, A-6, and $\mathrm{A}-7$ in $0.5 \mathrm{M} \mathrm{NaCl}$ aqueous solution are significantly higher than those in cadoxen. The large ratios of the $M_{w}$ in $0.5 \mathrm{M} \mathrm{NaCl}$ aqueous solution to those in cadoxen suggest aggregation of $\mathrm{A}$ gum in $0.5 \mathrm{M} \mathrm{NaCl}$ aqueous solution. The apparent aggregation number $\left(N_{\mathrm{ap}}\right)$ can be deduced from the mass of aggregates, namely $N_{\text {ap }}=M_{w}$ (in $\mathrm{NaCl}$ aq.) $/ M_{w}$ (in cadoxen). $N_{\text {ap }}$ are given in Table II. The dependence of $N_{\text {ap }}$ on $M_{w}$ in cadoxen is shown in Figure 3. Clearly, the aggregation numbers of $\mathrm{A}$ gum and its fractions increased with decreasing molecular weight, as has been reported. ${ }^{13}$ 
Table II. Experimental $M_{w},\left\langle S^{2}\right\rangle^{1 / 2},[\eta]_{0},[\eta]$, and $N_{\text {ap }}$ of samples in various solvents at $25^{\circ} \mathrm{C}$

\begin{tabular}{|c|c|c|c|c|c|c|c|}
\hline \multirow{2}{*}{ Sample } & \multirow{2}{*}{ Sovelnt } & \multirow{2}{*}{$M_{w} \times 10^{-5}$} & \multirow{2}{*}{$\frac{\left\langle S^{2}\right\rangle^{1 / 2}}{n m}$} & \multirow{2}{*}{$\frac{[\eta]}{m L g^{-1}}$} & \multirow{2}{*}{$\frac{[\eta]_{0}}{\mathrm{mLg}^{-1}}$} & \multirow{2}{*}{$\frac{[\eta]_{0 \mathrm{NaCl}}}{[\eta]_{\mathrm{cad}}}$} & \multirow{2}{*}{$N_{\mathrm{ap}}$} \\
\hline & & & & & & & \\
\hline A & $0.5 \mathrm{M} \mathrm{NaCl}$ & 79.0 & 105 & $5280^{\mathrm{a}}$ & 944 & 5.0 & 22 \\
\hline$A-5$ & $0.5 \mathrm{M} \mathrm{NaCl}$ & 128 & 99 & $6070^{\mathrm{a}}$ & 995 & 3.9 & 21 \\
\hline A- 6 & $0.5 \mathrm{M} \mathrm{NaCl}$ & 98.6 & 112 & $5490^{\mathrm{a}}$ & 1090 & 3.2 & 14 \\
\hline A-7 & $0.5 \mathrm{M} \mathrm{NaCl}$ & 90.1 & 97 & $5100^{\mathrm{a}}$ & 1050 & 3.1 & 8 \\
\hline A & Cadoxen & 3.67 & 57 & 188 & & & \\
\hline A-5 & Cadoxen & 6.18 & 74 & 254 & & & \\
\hline A-6 & Cadoxen & 7.26 & 77 & 337 & & & \\
\hline A-7 & Cadoxen & 11.4 & 83 & 339 & & & \\
\hline
\end{tabular}

${ }^{\mathrm{a}}$ In water.

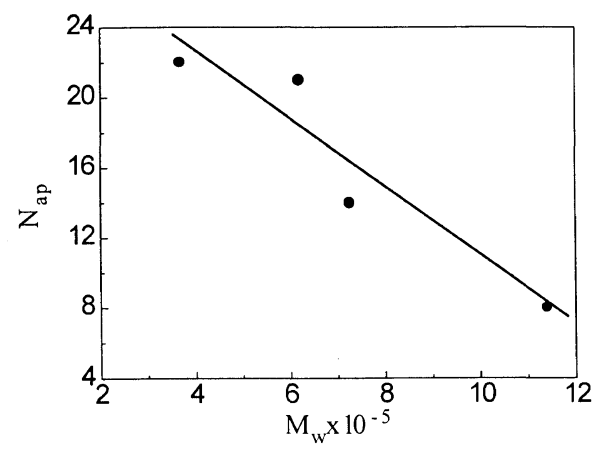

Figure 3. Dependence of aggregation number $N_{\text {ap }}$ on molecular weight $M_{w}$ for A gum in solution.

The fractions from A-1 to A-4 were not used in this work because of the presence of large gel particles in aqueous solution, resulting in failure of light scattering. This implies that fractions A-1 to A-4 may have much larger $N_{\text {ap }}$ than those used here. It was not possible to prepare usable fractions by precipitating A gum aqueous solution with isopropanol, because the water-solubility of A gum depends on aggregating number, molecular weight and content of uronic acid.

\section{Viscosity Behavior}

The intrinsic viscosity $[\eta]$ and zero shear-rate viscosity $[\eta]_{0}$ of the samples in water, $0.5 \mathrm{M} \mathrm{NaCl}$ aqueous solution and cadoxen are summarized in Table II. $[\eta]_{0}$ of the samples in $0.5 \mathrm{M} \mathrm{NaCl}$ aqueous solution are higher than $[\eta]$ in cadoxen, but the ratios of $[\eta]_{0}$ in $0.5 \mathrm{M} \mathrm{NaCl}$ aqueous solution to $[\eta]$ in cadoxen are much lower than those of the corresponding $M_{w}$. Usually, $[\eta]$ of the flexible polymer in water are lower than in cadoxen, because of the solvation. [ $\eta]$ of schizophyllan ${ }^{4}$ and xanthan $^{3}$ in aqueous solution are much higher than in $\mathrm{Me}_{2} \mathrm{SO}$ or cadoxen, and the ratios of $[\eta]$ in aqueous solution to those in $\mathrm{Me}_{2} \mathrm{SO}$ or cadoxen are higher than those of $M_{w}$, which decrease in $\mathrm{Me}_{2} \mathrm{SO}$ or cadoxen by factors of 3 and 2, respectively. The viscosity behavior of A gum differs substantially from that of the flexible single-chain and multiplex-stranded helix. Disruption of A gum aggregates in cadoxen may lead to extensive decrease in $[\eta]$, but the solvation in cadoxen causes increase in chain dimensions. For example, $[\eta]$ of amylose rises by a factor $\sim 2$ on passing from water to $\mathrm{Me}_{2} \mathrm{SO}{ }^{16}$

$[\eta]_{0}$ in $0.5 \mathrm{M} \mathrm{NaCl}$ aqueous solution and $[\eta]$ in

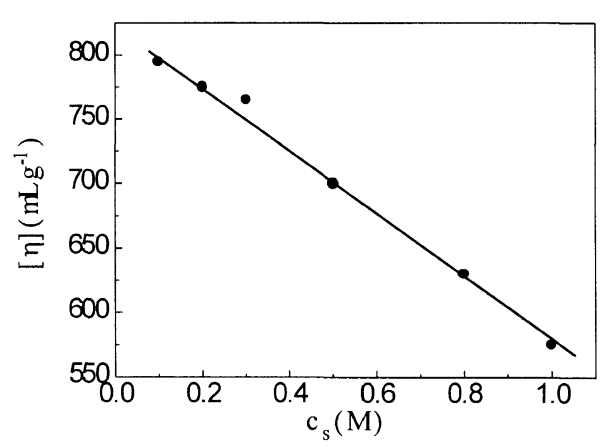

Figure 4. Salt concentration dependence of $[\eta]$ of A-6 at $25^{\circ} \mathrm{C}$.

cadoxen of A-6 and A-7 samples were significantly higher than those of $\mathrm{A}$ and $\mathrm{A}-5$, respectively. Interestingly, charge in the contents of A-6 and A-7 samples was larger than for A and A-5 as shown in Table I. Electrostatic repulsion between uronic acid groups thus be important in the enhancement of viscosity of A gum in solution. As given in Table II, the samples exhibit excessive high $[\eta]$ in pure water, owing to extension of chains caused by electrostatic repulsion between chrged groups. Therefore, A gum is a good thickening agent in water.

\section{Influence of Salt Concentration on $[\eta]$}

Figure 4 shows salt concentration $c_{\mathrm{s}}$ dependence of $[\eta]$ for $\mathrm{A}-6$ in desired $\mathrm{NaCl}$ concentration aqueous solution. $[\eta]$ decreased with salt concentration. Eisenberg et al. reported ${ }^{11}$ two block polyelectrolyte samples as a function of $\mathrm{NaCl}$ concentration, and found that at low salt concentration $\left(c_{\mathrm{s}}<0.2 \mathrm{M}\right)$ aggregation numbers initially increased with salt concentration and then eventually leveled off. The aggregation number of A gum in $\mathrm{NaCl}$ aqueous solution may increase with $c_{\mathrm{s}}$, but reduced dimensions caused by decrease of electrostatic force is likely to have stronger effect on [ $\eta]$ than enhancement of $N_{\text {ap }}$.

\section{Aggregation Process}

To study aggregation, sample A-6 was dissolved in $50 \%$ cadoxen, which disassociates aggregates to single chains, and then diluted by $0.5 \mathrm{M} \mathrm{NaCl}$ aqueous solution at once to a final solvent of $0.5 \mathrm{M} \mathrm{NaCl} / 3 \%$ cadoxen. Viscosity measurements were carried out as a function of time, and the time dependence of $\eta_{\mathrm{sp}} / c$ obtained from A-6 in 3\% cadoxen aqueous solution diluted with $0.5 \mathrm{M}$ $\mathrm{NaCl}$ aqueous solution is shown in Figure 5. $\eta_{\mathrm{sp}} / c$ 


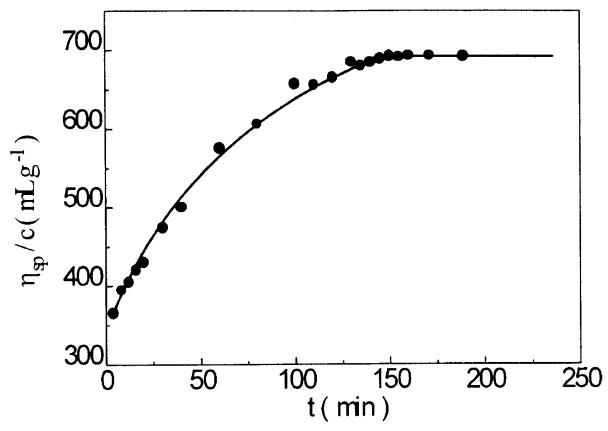

Figure 5. Aggregation-time dependence of $\eta_{\mathrm{sp}} / c$ of A-6 in $0.5 \mathrm{M}$ $\mathrm{NaCl} / 3 \%$ cadoxen at $25^{\circ} \mathrm{C}$

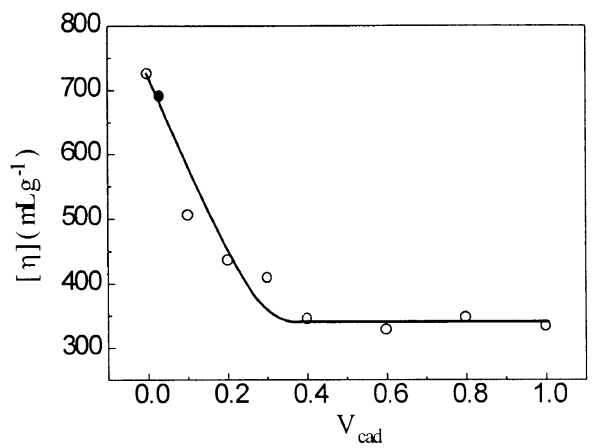

Figure 6. Plots of $[\eta]$ against $v_{\text {cad }}$ for A- 6 in $0.5 \mathrm{M} \mathrm{NaCl} /$ cadoxen mixtures at $25^{\circ} \mathrm{C}$. See the text for solid circle explanation.

increased with time from 0 to $150 \mathrm{~min}$, then kept constant $\eta_{\mathrm{sp}} / c$ for over one week, indicating stable aggregation. The aggregation of $\mathrm{A}$ gum forms more easily than schizophyllan, which formed associates $(c=0.194 \times$ $10^{-2} \mathrm{~g} \mathrm{~mL}^{-1}$ ) after $8 \mathrm{~h}^{4}$

Figure 6 shows that the dependence of $[\eta]$ on the volume fraction of cadoxen in the mixtures $\left(v_{\text {cad }}\right)$ for A-6 in $0.5 \mathrm{M} \mathrm{NaCl}$ aqueous/cadoxen mixtures. As $v_{\text {cad }}$ increased from 0 to 0.4 , the $[\eta]$ values decreased sharply, and then almost kept the constant with continuous increase of $v_{\text {cad }}$. This suggests that the aggregates were broken up to single chains in a range of $v_{\text {cad }}$ from 0 to 0.4 . The solid circle in Figure 6 refers to the value of $[\eta]$ obtained from A- 6 dissolved in $50 \%$ cadoxen and then diluted to $0.5 \mathrm{M} \mathrm{NaCl} / 3 \%$ cadoxen with $0.5 \mathrm{M} \mathrm{NaCl}$ aqueous solution. The results mentioned above are similar to those of glucan PC3 from Poria cocos sclerotium in water/cadoxen mixtures, in which the change of aggregation and disaggregation occurred in the range of $v_{\text {cad }}$ from 0.2 to 0.3 , and was reversible. ${ }^{9}$ These results proved that the aggregates of the polysaccharides were diassociated to single chains in cadoxen more readily than triple helix of schizophyllan in $\mathrm{Me}_{2} \mathrm{SO}^{4}$ and double-stranded helix of xanthan in cadoxen. ${ }^{3}$ When the weight fractions of $\mathrm{Me}_{2} \mathrm{SO}$ or cadoxen in the mixtures reached 0.87 and $0.7,{ }^{3,4}$ the triple helix or double helix melted to single chains.

\section{CONCLUSIONS}

The $M_{w}$ of Aeromonas gum was measured to be $7.90 \times 10^{6}$ in $0.5 \mathrm{M} \mathrm{NaCl}$ aqueous solution and $3.67 \times 10^{5}$ in cadoxen by light scattering, respectively. It indicated that $\mathrm{A}$ gum exists as aggregates in $0.5 \mathrm{M} \mathrm{NaCl}$ aqueous solution and mainly as single chains in cadoxen, and the apparent aggregation number was given to be $c a .22$. The aggregation number decreased with increase of the molecular weight of the sample. The change of aggregation and disaggregation of $\mathrm{A}$ gum in $0.5 \mathrm{M} \mathrm{NaCl}$ aqueous/cadoxen mixtures occurred from 0 to 0.4 of $v_{\text {cad }}$, and were reversible. Stable aggregation of A gum in $0.5 \mathrm{M}$ $\mathrm{NaCl}$ aqueous $/ 3 \%$ cadoxen was achieved after $150 \mathrm{~min}$. The aggregation of $\mathrm{A}$ gum in aqueous solution took place more easily and was broken in cadoxen than multiple helix chain. $[\eta]$ and $[\eta]_{0}$ of $\mathrm{A}$ gum in water and $0.5 \mathrm{M}$ $\mathrm{NaCl}$ aqueous solution were much higher than in cadoxen, and electrostatic repulsion between uronic acid groups was essential to the enhancement of viscosity of A gum in water.

Acknowledgments. We gratefully acknowledge the financial support from Asahi Chemical Industry Co., Ltd. of Japan. We also thank Dr. Rongping Zhu (National Research Center for Certified Reference Materials in Beijing) for making the light scattering measurements.

\section{REFERENCES}

1. S. Tanaka, Jpn. Kokai Tokyo Koho 89-13360, 6 March 1989, $8 \mathrm{pp}$

2. S. Tanaka, Jpn. Kokai Tokyo Koho 89-206971, 21 August 1983, $3 \mathrm{pp}$.

3. T. Sato, S. Kojima, T. Norisuye, and H. Fujita, Polym. J., 16, 423 (1984).

4. T. Norisuye, T. Yanaki, and H. Fujita, J. Polym. Sci., Polym. Phys., 18, 547 (1980).

5. K. D. Branham, D. L. Davis, J. C. Middleton, and C. L. Mccormick, Polymer, 35, 4429 (1994).

6. E. Y. Chu, Z. S. Xu, C. M. Lee, C. K. F. Sek, Y. Okamoto, E M. Pearce, and T. K. Kwei, J. Polym. Sci., B, Polym. Phys., 33, 71 (1995).

7. L. Zhang and L. Yang, Biopolymers, 36, 695 (1995).

8. L. Zhang, L. Yang, and J. Chen, Carbohydr. Res., 276, 443 (1995).

9. L. Zhang, Q. Ding, P. Zhang, R. Zhu, and Y. Zhou, Carbohydr. Res., 303, 193 (1997).

10. C. Wu, P. Wu, and X. Ma, J. Polym. Sci., B, Polym. Phys., 34, 221 (1996).

11. K. Khougaz, I. Astafieva, and A. Eisenberg, Macromolecules, 28, 7135 (1995)

12. H. Iatrou, L. Willner, N. Hadjichristidis, A. Halperin, and D. Richter, Macromolecules, 29, 581 (1996).

13. P. Vanhoorne and R. Jerome, Macromolecules, 28, 5664 (1995).

14. L. Zhang, L. Yang, D. Qing, and X. Chen, Carbohydr. Res., 270, 1 (1995).

15. T. Bitter and H. M. Muir, Anal. Biochem., 4, 330 (1962).

16. R. C. Jordan and D. A. Brant, Macromolecules, 13, 491 (1980). 